\title{
Dynamic game adaptation based on detection of behavioral patterns in the player learning curve
}

Citation for published version (APA):

Vassileva, D., \& Bontchev, B. (2018). Dynamic game adaptation based on detection of behavioral patterns in the player learning curve. In Proceedings of the 10th Annual International Conference on Education and New Learning Technologies: EDULEARN2018 (pp. 8182-8191). IATED Academy.

https://doi.org/10.21125/edulearn.2018.1905

DOI:

10.21125/edulearn.2018.1905

Document status and date:

Published: 01/01/2018

Document Version:

Peer reviewed version

Document license:

CC BY-NC-SA

Please check the document version of this publication:

- A submitted manuscript is the version of the article upon submission and before peer-review. There can be important differences between the submitted version and the official published version of record. People interested in the research are advised to contact the author for the final version of the publication, or visit the DOI to the publisher's website.

- The final author version and the galley proof are versions of the publication after peer review.

- The final published version features the final layout of the paper including the volume, issue and page numbers.

Link to publication

\section{General rights}

Copyright and moral rights for the publications made accessible in the public portal are retained by the authors and/or other copyright owners and it is a condition of accessing publications that users recognise and abide by the legal requirements associated with these rights.

- Users may download and print one copy of any publication from the public portal for the purpose of private study or research.

- You may not further distribute the material or use it for any profit-making activity or commercial gain

- You may freely distribute the URL identifying the publication in the public portal.

If the publication is distributed under the terms of Article 25fa of the Dutch Copyright Act, indicated by the "Taverne" license above, please follow below link for the End User Agreement:

https://www.ou.nl/taverne-agreement

Take down policy

If you believe that this document breaches copyright please contact us at:

pure-support@ou.nl

providing details and we will investigate your claim.

Downloaded from https://research.ou.nl/ on date: 26 Apr. 2023 


\title{
DYNAMIC GAME ADAPTATION BASED ON DETECTION OF BEHAVIORAL PATTERNS IN THE PLAYER LEARNING CURVE
}

\author{
Dessislava Vassileva ${ }^{1}$, Boyan Bontchev ${ }^{2}$ \\ ${ }^{1}$ Scientific Research Department (NIS), Sofia University St. KI. Ohridski (BULGARIA) \\ ${ }^{2}$ Faculty of Mathematics and Informatics, Sofia University St. KI. Ohridski (BULGARIA)
}

\begin{abstract}
In educational serious games, the learning curve of a player represents his/her progress in acquiring cognitive abilities and new knowledge necessary for solving the game challenges. Hence, it is very important for an adaptive serious game to have a mechanism for detection of patterns of player's learning curve in playing time. The paper presents the application of a game adaptation method based on automatic and dynamically detection of specific learning curves at runtime within a 3D video game of car driving in various weather conditions. The method uses a client-side software component called "Player-centric rule-and-pattern-based adaptation asset" and developed within the scope of the RAGE (Realising and Applied Gaming Ecosystem) H2020 project. The component is incorporated into a 3D car driving video game in order to enable a dynamic detection of different patterns of player performance. It allows the video game scenario to be adapted to each player by providing appropriately for him/her challenges and game features. We carried out a practical experiment with students from Sofia University, Bulgaria, where we found that adaptation of game difficulty by applying the RAGE software component resulted to improved game playability.
\end{abstract}

Keywords: game adaptation, player learning curve, detection, behaviour pattern, game component, RAGE.

\section{INTRODUCTION}

Nowadays, video games became part of the culture of people of all ages and their popularity grows every day [1]. They are amusing and engaging, and besides entertainment, they are also used in various fields such as medicine, engineering, education, etc. to acquire new knowledge and skills [2]. The main goal of video games in these areas is to create gameplay scenarios for learning new knowledge and training skills based on tracking player progress, i.e. level of performance, acquired knowledge, or skills. One of the methods for player progress monitoring is using of learning curves. A learning curve presents the course of progress made in learning new skills and knowledge over time [3]. In video games, the learning curve illustrates the specific performance to an individual player in acquiring of new playing skills, cognitive abilities and knowledge to solve the challenges in the game, usually in a restricted time [4]. Detection of the player learning curve is very important for the implementation of an effective learning process through playing a game because it enables to identify the current state of a player and, hence, what activities (gameplay scenarios with different difficulties, learning exercises, etc.) are appropriate for him/her. A learning curve is different for each player [5]. This fact implies developing an adaptive gameplay scenario depending on it that adjusting of game difficulty and challenges in order to retain player motivation, engagement, and efficiency of the learning process [6].

In this study, we present a method for dynamic game adaptation based on detection of behaviour patterns in the player learning curve and, as well, an experimental study that evaluates its effectiveness. The adaptation according to this approach was accomplished using a game component named "Player-centric rule-and-pattern-based adaptation asset" and developed within the scope of the RAGE (Realising and Applied Gaming Ecosystem) H2020 project. The component is integrated within a car driving video game and allows dynamic registration and detection of behaviour patterns of specific player learning curves representing overall player performance over time (OPP). When a pattern behaviour in the player learning curve is identified a pre-defined event is triggered and weather conditions (level of illumination, fog, rain, etc.) in the game are changed. The goal of weather changes in the game is to provide the most appropriate gameplay scenarios in order to improve driving skills of the player depending on his/her current OPP.

A practical experiment was conducted with students from Sofia University, Bulgaria, in order to evaluate the effect of a dynamic adaptation of the car driving game according to pre-defined behaviour 
patterns that are detected at runtime by the RAGE game component. The practical experiments include identification of characteristic patterns in individual learning curves and, next, using the dynamic pattern detection for tailoring some features of the game having impact on OPP. Thus, the experimental study consisted of two stages. In the first stage, we identified specific patterns repeated in individual learning curves while students played a car driving video game without adaptation. During the second stage, students of the study group played the same game but adapted by means of patterns in individual learning curves detected through the RAGE "Player-centric rule-and-patternbased adaptation asset". At the same time, students of the control group played the non-adaptive version of the game. After the game session, participants completed a post-game questionnaire about their gaming experience and the impact of adaptation over player satisfaction, perceived learnability and effectiveness, immersion in the game world, motivation, and emotional state of the individual player. Results of conducted experiment demonstrate preferences of students to the car driving game adapted by applying the RAGE game asset for detection of behavioural patterns in the player learning curve. According to students' opinion, the adapted version of the game is more immersive, engaging and effective. The found results provide an answer to the main research question: How behavioural patterns of player performance can be found in the player learning curve in a more complex online 3D video game in order to be applied for a straightforward player-centric adaptation leading to an improved game playability?

\section{MOTIVATION}

The present research aims at automatic detection of the learning curve reflecting player performance achieved at runtime of playing a 3D video game for car driving at various weather conditions. The dynamic detection of learning curve patterns is very important because the game adaptation based on learning curve patterns is more adequate and reasonable than that one based on metric thresholds. The section briefly outlines the methods of using player-centric adaptation of difficulty in video games and introduces the concept of learning curves used in terms of serious games.

\subsection{Player-Centric Adaptation in Video Games}

The most important goal for each one video game is to provide to players high level of fun and enjoyable experience. It can be accomplish trough keeping balance between available challenged game situations and skills of the player to deal with them. When this balance is achieved the player is fall in the zone of flow. Mihaly Csikszentmihalyi [7] introduced the concept of flow - the state in which people immerse themselves fully in doing their favorite activities. The concept consists of eight important elements of flow, namely:

1 clearly defined goals,

2 balance between ability level and level of challenging activity,

3 direct and immediate feedback,

4 high degree of concentration on executed task,

5 feeling of self disappears with deep but effortless involvement while being in flow but emerges stronger afterwards,

6 transformation of time,

7 sense of personal control without worries about failures and, finally,

8 intrinsic rewards.

However, different players are impressed by different things, in different ways, and in different game periods. To let game developers to be able to adapt the game according to player personal expectations and needs, the last have to be monitored and analyzed including player behavior, achievements and emotional state in playing time. Basically, there are three gameplay adaptation options implemented through dynamically changes in the player character, in the non-player characters, or in the game world (e.g. game environment, conditions, rules, graphics, etc.) [8]. Moreover, methods and techniques from player-centric games can be used successfully for this goal.

Player-centric adaptive games adapt game mechanics and environment depending on the player model. Usually, the player model is composed of three main players' behavioural features - cognitive and emotional issues, and player preferences. Other factor important for adaptation in the player- 
centric adaptive games is the player performance. In order to be the game adaptation more effectiveness, the player model have to be able to be modified. Thereby, changes in the player behaviour and/or player performance can result to changes in the player model that can lead to changes in the adaptation mechanism. This requires the implementation of a dynamic model of the player and constant monitoring of current player interactions, emotional status and acquired skills [6]. Thus, simultaneously, the video game and the player will be responsive to affective interactions between themselves in an affective feedback loop. Novak et al. [9] summarized the main three points of game adaptations related to the affective video games:

- supporting adaptive tasks or game situations - game objectives can be assigned explicitly as a game task or implicitly in the game scenario;

- tailoring of game difficulty level - it must be in accordance with the current player's abilities and, thus, he/she to be in the zone of optimal playing experience;

- adjustment of game graphic elements - it includes an adaptation of audio-visual effects such as level of intensity of light, appearing in fog, user interface, etc.

\subsection{Learning Curves}

The psychologist Hermann Ebbinghaus [10] for the first time introduced the term "learning curve" when he conducted an investigation related to human memory and recall. Ebbinghaus examined the reasons for less forgetting if learning is retrieved and repeated at regular intervals. In this research he found that the recalling process is more effectively when frequency of repetition is distributed in an appropriate interval instead of presenting of learning material as a long sequence of information. $\mathrm{He}$ used a curve called "learning curve" in order to represent graphically forgetting processes. Where the learning curve is steep, the learning process and acquisition of knowledge is fast.

Initially, the concept learning curves appeared only in the educational and behaviour psychology, however, now it is widely used also in other areas like economics, statistics, video games, etc. Theodore Wright [11] followed the same approach like Ebbinghaus for presenting the impact of training over total cost of a unit in aircraft industry through a graphic called "experience curve". Learning curve is known, as well as, "progress curve", "improvement curve", "efficiency curve", "forgetting curve", etc., but in fact these terms are synonyms.

Learning curves are highly used in educational serious games and technology enhance learning systems. They provide a visual representation of the ratio between the time spent by players or learners on gaining new learning material and cognitive abilities (shown on the horizontal $x$ axis) to acquired knowledge and skills to solve the challenges of the game (shown on the vertical y axis). The concept of learning curves provides an effective way for defining or predicting how much time might be necessary for attaining particular competence. Depending on conditions of conduction of the learning process (level of proficiency of the learner, motivation of the learner, difficulty of learning material, etc.), there are four types of learning curves: diminishing-returns learning curve, increasing returns learning curve, increasing-decreasing return learning curve, and increasing-decreasing-return learning curve [12].

It is crucially important for the learning process, both the game designer and educational instructor to have expectation for the player performance progress and depending on his/her current results to provide dynamically a game scenario with appropriate learning task difficulty, available challenges and graphical effects. Thereby, the player will be in the zone of flow, i.e. optimal experience [13] that will lead to better immersion, greater motivation and learning performance.

\section{METHODOLOGY}

The research method applied in the current study count on practical experiments with playing a video game with adaptation realized according to specific patterns detected automatically in the learning curve of performance shown by an individual player. After the game session, each participant was asked to fulfill online a reduced form of the Game Experience Questionnaire (GEQ) questionnaire [14].

\subsection{Recognition of Patterns in Time Sequences}

For an automatic, run-time detection of specific patterns in the learning curve of an individual player, we applied a software component called "Player-centric rule-and-pattern-based adaptation asset" 
developed in the scope of the RAGE (Realising and Applied Gaming Ecosystem) H2020 project [15]. The components uses a formal description of patterns and rules for on-the-fly detection of the patterns and rules within dynamically produced time sequences, e.g. within the evolution of game player performance over time. The Rule-and-Pattern-Based Adaptation component can be used for two purposes:

1 For monitoring of particular player-centric metrics such as regarding outcomes, emotional status and/or playing style of an individual player - by dynamic detection of specific patterns or/and rules in the curve of given player metric;

2 For realization of dynamical adaptation according to a specific change either of a player metric over time or of its features such as mean, deviation and moving average, within a desired time window.

The component initialization process includes four important issues:

1 Registration of one or more player-centric metrics or their features for monitoring within a predefined time window by the component, such as metrics regarding player's performance (knowledge and intellectual abilities), effective status (emotional experiences, feelings and motivation), playing style, etc. - the variation of the registered metrics will be analysed by the component.

2 Formal definition of triggering rules or patterns in evolution of a metric or its feature like mean, deviation and moving average - one or more rules or patterns of change of an already registered metric or its feature are to be defined by using a simple syntax.

3 Definition of adaptation event handlers - for each adaptation event triggered upon specific occurrence of a rule or a pattern, a specific custom event handler should be defined in order to be executed at run-time, acting as adaptation method changing some game features regarding game mechanics, dynamics and aesthetics [16].

4 Setting the global time and time window at the software component - the game developer can set/reset the internal timer at any time in order to synchronize it to the game engine.

The formal definition of triggering rules or patterns includes name of the rule/pattern, metric associated with the rule/pattern (a metric can be associated with more than one patterns), optional metric feature (e.g., mean or moving average), sequence/interval of moments of time, and a sequence of values related to metric value. The last two sequences can be absolute, relative, or rule based [15]. As well, the formal definition may include a fitting line determining a range, where metric values may vary. The fitting line consists of following two properties:

- Accuracy (confidence interval) - represents the maximal deviation of the registered game metric values from the expected pattern.

- Recall (confidence level) - represents the percentage of all registered game metric values that have to be within the defined range.

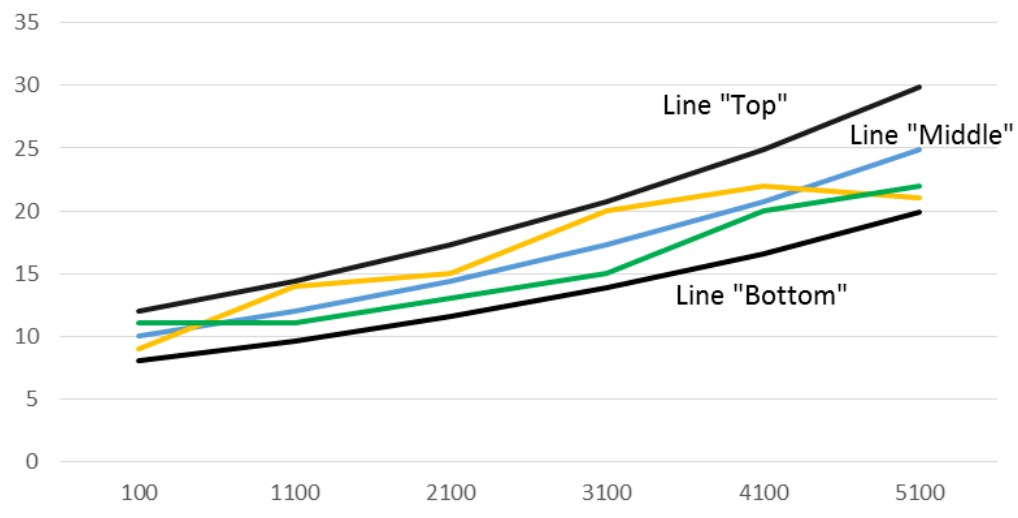

Figure 1. Pattern example of player performance increasing with $20 \%$ each second for a period of 5 seconds [14]. 
Fig. 1 presents a pattern example of player performance (the blue line) that increases with $20 \%$ at each second, for a period of 5 seconds, defined with accuracy $80 \%$ (represented by the top line with $20 \%$ over the blue pattern line, and by the bottom line with $20 \%$ below the blue line) and confidence level $100 \%$ (i.e., with no outliers).

The Player-centric rule-and-pattern-based adaptation component can be easily integrated into any video game either as a client-side or as a server-side component, by using its DLL and API [17]. When the initialization process is finished and the game starts, initially, the game asset receives as input registration requests of player-centric metrics. The metric represent a property of the player such as individual performance (as in the case of this article), emotional status, playing style, etc. Each metric is associated with one or more patterns modelling a game event (e.g. increasing player outcomes) and defined by simple formal definitions of rules. The goal of these rules is to be set variation of values of metrics during the playing time and they are defined by simple but powerful syntax. Moreover, each pattern can be associated with a feature, such as average or moving average within a desired time window.

\subsection{An Online Video Game Simulating Car Driving}

The Player-centric rule-and-pattern-based adaptation component was integrated within an online 3D car driving video game in order to detect dynamically specific player learning curves representing the overall player performance (OPP) over time [14]. The objective of the game is to drive a car with a minimum number of accidents at the highest possible speed, taking into account different driving conditions such as low visibility due to fog and driving shortly before dusk, and a slippery road due to rain (fig. 2). The speed is displayed on the speedometer and the progress of the current lap is represented by a growing green circle around the speedometer. The control of the vehicle is with the arrow keys. There are no penalty points for accidents; however, committed accidents affect OPP. In fact, OPP depends on average velocity, number of accidents, and their impact on the vehicle (measured by sinus of the angle between the car direction vector and the hit body orientation) [15]. The evolution of OPP (raw values or it moving average) forms a learning curve and is specific for each player but depends strongly on the curves on the road ad, as well, on the applied driving conditions such as fog, rain, and nightfall.
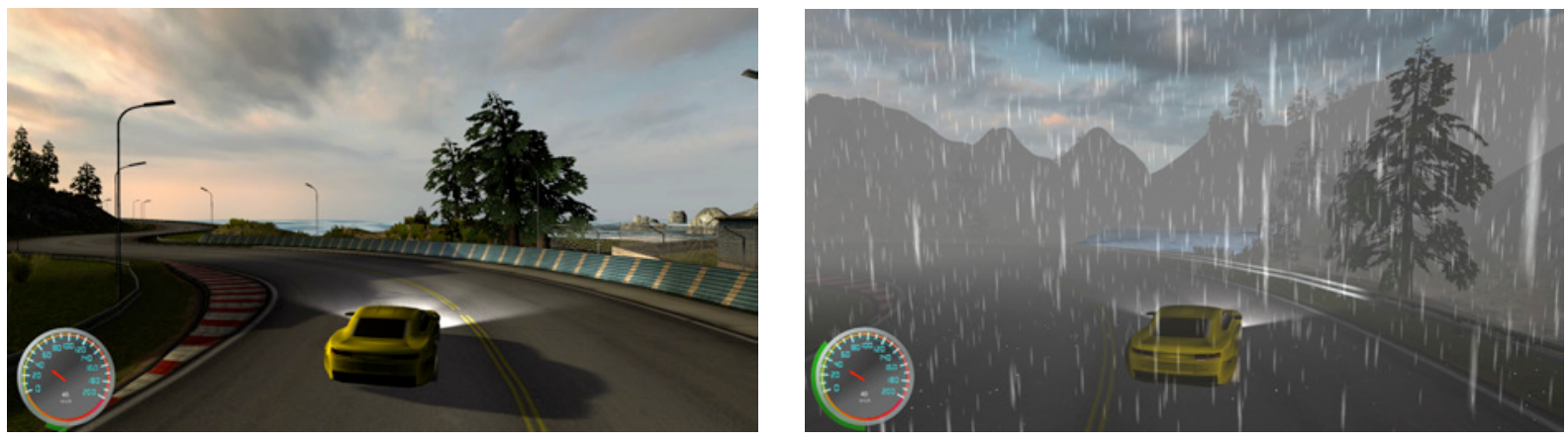

Figure 2. Views of the game prototype - driving in good weather (left) and in a foggy, rainy day (right).

The game requires a passage of three turns (laps) of a road containing different type of curves. At each next turn, weather conditions and illumination worsen, making driving increasingly difficult. On the first turn, the player enjoys sunny daylight and nice clear weather. On the second lap, a fog appears and the visibility decreases. On the last turn, driving is at rain and the road becomes slippery and darker. Therefore, each turn represents a higher level in the game providing higher playing difficulty. Within the second and the third level (i.e. driving turn), the game apply adaptation of some game mechanics (friction to the road at the rain, or/and visibility at the fog, or/and illumination at nightfall). These game mechanics are adjusted to the learning curve of the individual player, namely by detection of specific patterns of OPP pointing out to a trend of changing the player outcome over time.

We conducted preliminary experiments with the game for detection of type of possible learning curves and patterns of the evolution of the moving average of OPP and its mean and moving average for each one driving turn (level). During the experiments, we found three main types of specific patterns of increase and decrease of moving average in a 10s time window: 
1 Strong increase/decrease - representing a change (increase or decrease) in OPP progression with $80 \%$ for a period of 10 seconds;

2 Moderate increase/decrease - means a change of OPP with $40 \%$ for a period of 10 seconds;

3 Slow increase/decrease - for cases of a change of OPP with $20 \%$ for a period of 10 seconds.

It was interesting that we detected the same patterns during driving at various road conditions, i.e. during all the three turns of the road. This allowed us to apply the events triggered for the detected patterns for adaptation of the mechanic of the game. In order to maintain the player in flow (i.e. in a state of optimal gaming experience) [13], we adjusted the game difficulty as follows:

- In cases of a detected pattern of moderate (or strong) increase of OPP, we increased the game difficulty by $10 \%$ (or $20 \%$ ) until reaching the maximum game difficulty;

- In cases of a detected pattern of moderate (or strong) decrease of OPP, we decreased the game difficulty by $10 \%$ (or $20 \%$ ) until reaching the maximum game difficulty.

Thus, we adjusted game difficulty stepwise - by $10 \%$ for a moderate change and by $20 \%$ for a strong change in OPP, in order to realize a smooth transition to the new difficulty. The changes of difficulty included variation of density of the fog and of the rain, adjusting the light and the slipperiness of the road.

\subsection{Experimental Procedure}

For conducting the practical experiments, the adaptive video game was built for both the Web browsers (available at a Web page with instructions how to play) and Windows platform (available for downloading as a desktop executable). Both the versions supported server-side logging each second of the player metrics (i.e., OPP and the impact of eventual accidents), found patterns, and triggered adaptation events. The participation was entirely anonymous and voluntarily. Freelancers were invited to participate the study by sending emails. They had the option to play the game either through a Web browser with a Unity plugin, or as a downloadable file. They were asked to play at least one game until the end (i.e., to finish the third level) before to fulfill online a reduced form of the Game Experience Questionnaire (GEQ) questionnaire [14] plus several additional questions about estimation of the game adaptivity. The GEQ questions were 36 (all translated in Bulgarian) and asked issues about competence, immersion, flow, tension, challenge, and positive/negative affect felt by the player during playing the car driving game.

We followed the same procedure for practical experiments with a non-adaptive version of the same game, in order to have a control group of participants allowing us to find eventual differences in reported game experience. Participants of both the control and study groups were not aware of which game version they play with - adaptive or non-adaptive.

\section{RESULTS}

The section presents some of the initial results of the case study exploring the dynamic player-centric adaptation of game difficulty and visual effects in the car driving video game, based on behavioural patterns detected at run time in the learning curve of individual players. The study group consisted of 24 volunteers, students at the Faulty of Mathematics and Informatics and Sofia University, Bulgaria, participating the experiment following the procedure described over. They had good gender balance 11 boys and 13 girls, at average age of $M=22.2667$ years $(S D=3.7239)$. The majority of them reported to have some gaming experience: for the Likert scale from ' 1 - I have never or rarely played video games', up to ' 5 - I play quite often video games', we received answers with $M=3.5$ with $S D=1.2854$. The preferable game genre appeared to be action/adventure games. On the other hand, we invited volunteers with similar age profile, gender balance, and gaming experience to join a control group and to test the non-adaptive version of the same game. Participants of both the group played the game (adaptive or non-adaptive) online and, next, fill in the same questionnaire (without getting know which version of the game they have played with - adaptive or non-adaptive).

As explained, the adaptation of the game difficulty was combined with adjusting some audio-visual effect such as density of fog and rain and intensity of daylight. All the changes of game mechanics resulted from patterns found in the learning curve of the moving average of OPP of an individual player. Fig. 3 presents a graphic of the evolution of OPP for the three levels of the game, the changes 
of its moving average calculated for a 10 s period of time (the blue dotted line), and patterns of slow, moderate and strong increase (INCR) or decrease (DECR) of the moving average of OPP (as explained in section 3.2). Just for illustration, the patterns are shown as values of 10 (slow), 20 (moderate) and 30 (strong) change of the OPP moving average. Only patterns of moderate and strong change are taken in consideration by invoking changes in game mechanics as explained in 3.2. All the patterns are applied for the moving average rather than the raw OPP time sequence as far as the raw sequence is not smooth and has for some times sequences of strong up's and down's, which hampers detection of the patterns. In fact, all the strong falls of OPP are due to accidents (collisions of the car into the containment), which decrease OPP due to a reduction of velocity and collision impact.

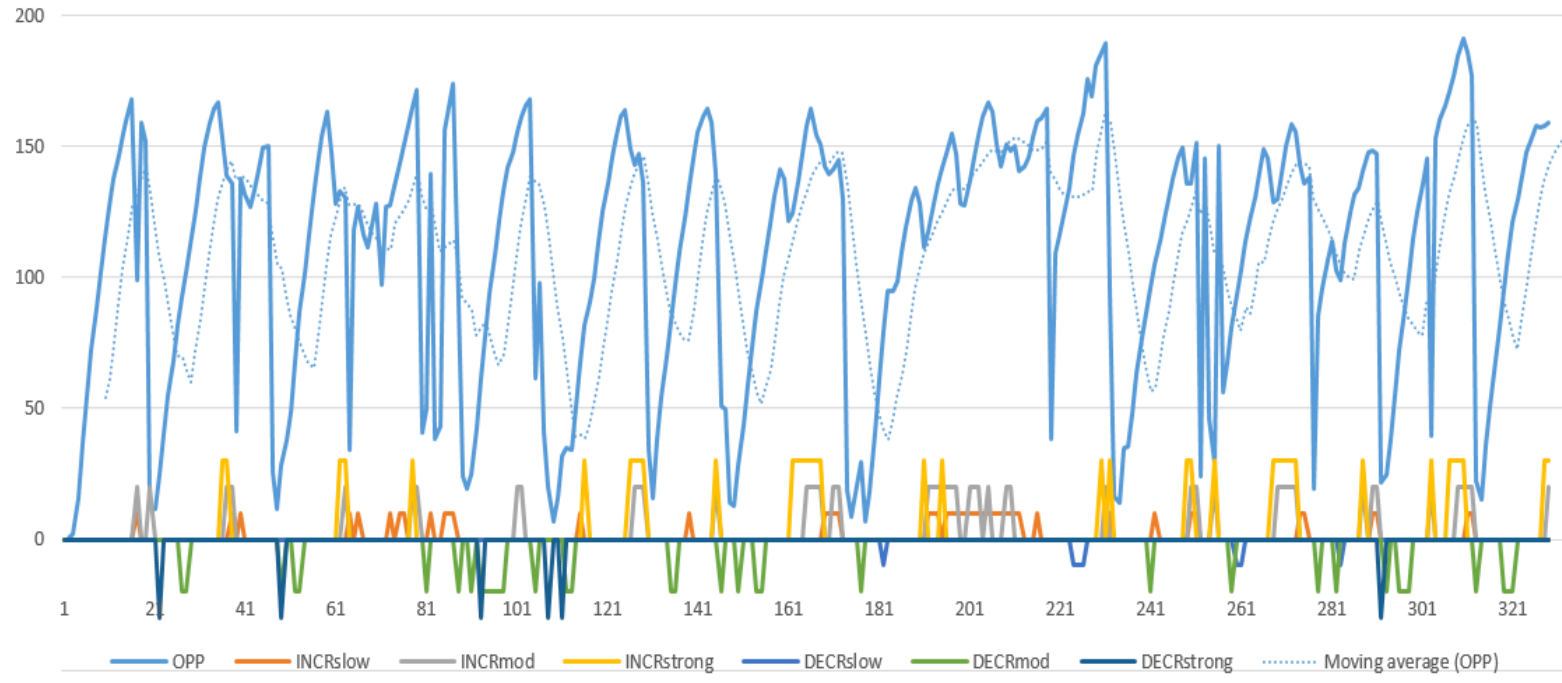

Figure 3. OPP, its 10s moving average, and found patterns for one of the players.

The player of both the study and control group played one or more game sessions respectively with the adaptive or non-adaptive version of the car driving video game. Next, they answered the questions of the same online questionnaire. Table 1 presents results about the game experience in adaptive and non-adaptive video games applying a 5-level Likert scale (). The values of mean (M), standard deviation (SD), and standard error (SE) were obtained for the seven indicators of gaming experience, namely positive affect, competence, immersion, flow, tension, challenge, and negative affect. The mean value of each indicator for both the adaptive or non-adaptive games was calculated as an average of the mean values of the corresponding questions about the component [14]. The last row of the table provides the differences between the respective means for both the adaptive or non-adaptive games. All the differences are statistically significant at $p$-value less than 0.001 . While all the differences are greater than almost half a Likert point, which provides an eloquent evidence for the benefits of the game adaptation based on behavioural patterns found in the learning curve of the player. The highest differences appeared to be for competence, positive affect, and tension. Unlike all the differences reported in table 1, these ones regarding the mean values of tension and negative affect are negative, which is another prove of the benefits brought by the adaptation - the adaptive game creates less feeling about tension and negative effect than the non-adaptive one. Therefore, the adaptation of game difficulty was reported to improve substantially all the GEQ indicators.

Table 1. Results about the game experience in adaptive and non-adaptive video games.

\begin{tabular}{c|c|c|c|c|c|c|c}
\hline Statistic & $\begin{array}{c}\text { Positive } \\
\text { Affect }\end{array}$ & Competence & Immersion & Flow & Tension & Challenge & $\begin{array}{c}\text { Negative } \\
\text { Affect }\end{array}$ \\
\hline M (adapted game) & 3.6500 & 3.3417 & 3.5069 & 2.9417 & 2.0417 & 3.1583 & 2.0583 \\
\hline SD & 0.6359 & 0.4353 & 0.6207 & 0.7494 & 0.8108 & 0.7575 & 0.8657 \\
\hline SE & 0.1298 & 0.0889 & 0.1267 & 0.1530 & 0.1655 & 0.1546 & 0.1767 \\
\hline M (non-adapted game) & 2.8627 & 2.2641 & 2.8375 & 2.462 & 2.7616 & 2.6617 & 2.6384 \\
\hline Difference & $\mathbf{0 . 7 8 7 3}$ & $\mathbf{1 . 0 7 7 6}$ & $\mathbf{0 . 6 6 9 4}$ & $\mathbf{0 . 4 7 9 7}$ & $\mathbf{- 0 . 7 2 0 1}$ & $\mathbf{0 . 4 9 6 6}$ & $\mathbf{- 0 . 5 8 0 1}$ \\
\hline \hline
\end{tabular}


Next to the GEQ questions, we asked players about their estimation of the game adaptivity. The first question of this group asked if the player did really feel the adaptation of game difficulty. Fig. 4 provides the distribution of the answers upon 5-level Likert scale, for the players of the adaptive car driving game. As shown in the chart, about one third of the respondents reported level " 5 - definitively yes" and another half of them approve having realized the adaptivity al level " 4 - rather yes". The results prove the tangible effect of the adaptation based on patterns found in learning curve of the player.

\section{Did you feel the adaptation of the game difficulty?}

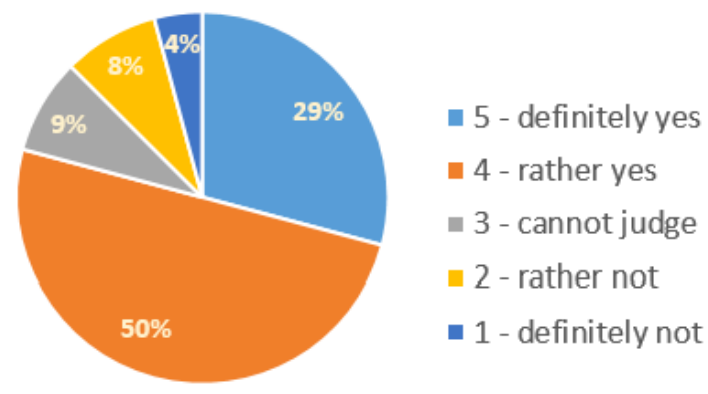

Figure 4. Level of perceived adaptation of game difficulty.

Next six questions of the questionnaire addressed the perceived impact of the game difficulty adaptation over the player character measured by means of the same Likert scale. Fig. 5 represent bar charts for the results about the adaptation impact over the player character addressed by six components:

- Player satisfaction - degree of fun, disappointment and attractiveness of playing);

- Perceived learnability - ability for acquiring learning skills);

- Perceived effectiveness - time to achieve the goal upon a balance between skills and challenges that need to be overcome)

- Immersion in the game world;

- Motivation - including issues such as encouragement, curiosity, and perceived selfimprovement during the play;

- Emotional state of the individual player.

All these impacts are reported to be rather high especially the influence over the satisfaction and the emotional state of the player. The smallest impact was reported over game learnability, which probably has to do with the genre of the experimental game. Most probably, experiments with real educational game will provide different results about enhancement of learnability thanks to game adaptation.

Impact of the adaptation over the player character

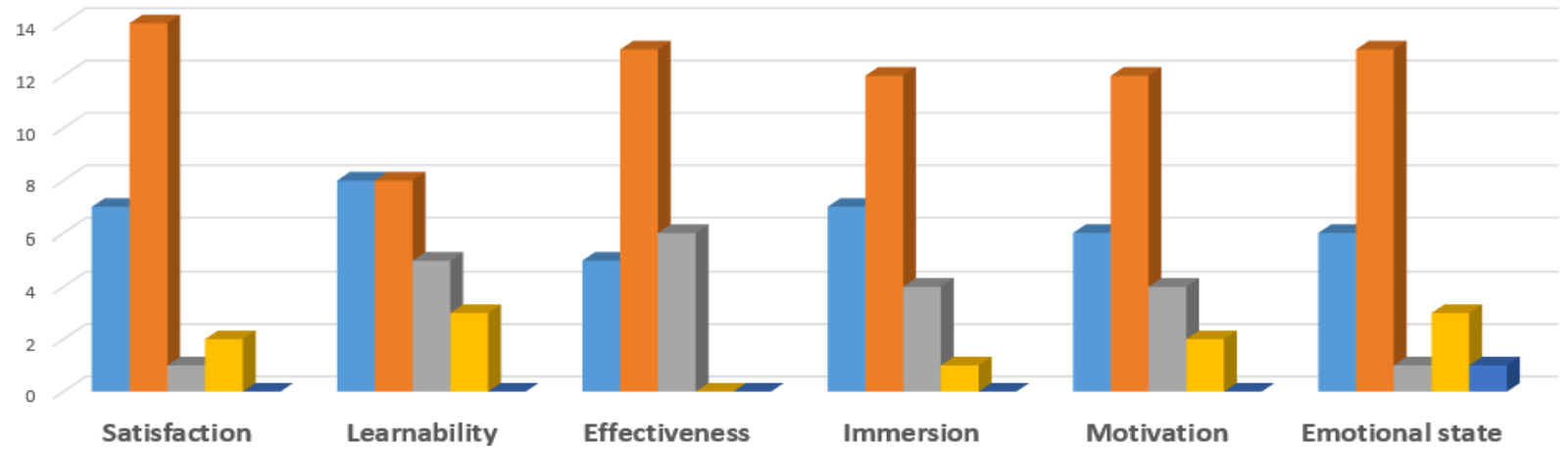

$\square 5$-definitely yes $\square 4$-rather yes $\quad 3$ - cannot judge $\square 2$-rather not $\square 1$-definitely not

Figure 5. Evaluation of the impact of adaptation of game difficulty over the player character. 


\section{CONCLUSIONS}

Adaptation of difficulty in digital games continues being a challenge, while promising many benefits such as better gaming experience, higher engagement, and better motivation to play the game [4, 9]. Such adaptation can be realised based on three main types of player-centric indicators: outcomes of the individual player (i.e. his/her achievements during the play), emotional state (emotions and/or arousal), and playing style [6]. The paper represented an easy and straightforward way of dynamic tailoring game difficulty in a car driving 3D video game based on automatic detection of patterns in the learning curve of the overall player performance. Game adaptation based on such learning curve patterns seems to be more effective and reasonable than that one based on metric thresholds due to the fact player performance varies from player to player - one cannot fix given performance level as global thresholds valid for all the players. At the same time, the adaptation applying learning curve patterns appears to be much easier for realization than tailoring game features according to emotional state or playing style, that need to be recognized by other player metrics [18]. As well, usage of components such as the RAGE "Player-centric rule-and-pattern-based adaptation asset" makes the adaptation process very simple and efficient.

The paper reported some optimistic results about an improved gaming experience thanks to applying adaptation based on learning curve patterns. The responses to the GEQ questionnaire revealed statistically significant improvements over all factors of game experience compared to the nonadaptive version of the same game, namely over the positive affect, competence, immersion, flow, tension, challenge, and negative affect. Besides that, the survey proved significant enhancements over the player satisfaction, perceived learnability and effectiveness, immersion in the game world, motivation, and emotional state of the individual player.

Further analyses are needed in order to find the changes of the game parameters and achieved results by each individual player, such as average velocity and OPP, total number and impact of committed accidents, and time for finishing the game. These parameters have to be studied for both the adaptive and non-adaptive versions of the game. As well, the adaptation of difficulty applying learning curve patterns should be compared to affect-based adaptation in order to find out the benefits of these different ways of tailoring the difficulty in video games.

\section{ACKNOWLEDGEMENTS}

The research leading to these results has received funding from the EC H2020 project RAGE (Realising an Applied Gaming Eco-System), Grant Agreement No. 644187, and from and the APOGEE project, funded by the Bulgarian National Science Fund, Grant Agreement No. DN12/7/2017.

\section{REFERENCES}

[1] S. Egenfeldt-Nielsen, J.H. Smith, and S.P. Tosca, "Understanding video games: The essential introduction", Routledge; 2015.

[2] C. S. Green, R. Li, and D. Bavelier, "Perceptual learning during action video game playing", Topics in Cognitive Science, 2(2), pp.202-216, 2010.

[3] E. Stump, "All about learning curves", Society of Cost Estimating and Analysis Conference Paper, Galorath Incorporated., El Segundo, CA, pp. 1-78, 2002.

[4] F. Bellotti, R. Berta, A. De Gloria, and L. Primavera, "Adaptive experience engine for serious games", IEEE Transactions on Computational Intelligence and Al in Games, 1, no. 4, pp.264280, 2010.

[5] C. Linehan, G. Bellord, B. Kirman, Z. H. Morford, and B. Roche, "Learning curves: analysing pace and challenge in four successful puzzle games", Proc. of the first ACM SIGCHI annual symposium on Computer-human interaction in play, ACM, pp. 181-190, 2014.

[6] B. Bontchev, "Adaptation in Affective Video Games: A Literature Review", Cybernetics and Information Technologies, Vol. 16, No 3, pp.3-34, DOI: 10.1515/cait-2016-0032, 2016.

[7] M. Csikszentmihalyi, "Flow: The Psychology of Optimal Experience", Harper Perennial, London, 1990. 
[8] N. Ravaja, T. Saari, J. Laarni, K. Kallinen, M. Salminen, J. Holopainen, A. Järvinen, "The Psychophysiology of Video Gaming: Phasic Emotional Responses to Game Events", Proc. of DiGRA'2005 Conf., 2005.

[9] D. Novak, M. Mihelj, and M. Munih, "A survey of methods for data fusion and system adaptation using autonomic nervous system responses in physiological computing", Interacting with Computers, 24, pp.153-172, 2012.

[10] H. Ebbinghaus, "Memory", Teachers College, New York, 39, 1913.

[11] T. P. Wright, "Factors affecting the cost of airplanes", Journal of the aeronautical sciences, Vol.3, No 4, pp. 122-128, 1936.

[12] D. G. Arce, "Experience, Learning, and Returns to Scale", Southern Economic Journal, 80(4), pp. 938-947, 2014.

[13] M. Csikszentmihalyi, "Finding Flow: The Psychology of Engagement with Everyday Life", New York, Basic Books, 1997.

[14] L. Nacke, Affective Ludology: Scientific Measurement of User Experience in Interactive Entertainment, Doctoral Dissertation, Blekinge Institute of Technology, 2009.

[15] B. Bontchev and D. Vassileva, "Detection of player learning curve in a car driving game", Proc. of $12^{\text {th }}$ Annual Int. Technology, Education and Development Conference (INTED'2018), IATED, Valencia, Spain, ISBN: 978-84-697-9480-7, pp.9302-9311, 2018.

[16] A. Parnandi and R. Gutierrez-Osuna, "A comparative study of game mechanics and control laws for an adaptive physiological game". Journal on Multimodal User Interfaces, pp.1-12, 2014.

[17] A. Georgiev, A. Grigorov, B. Bontchev, P. Boytchev, K. Stefanov, , W. Westera, R. Prada, P. Hollins, and P. Moreno, "The RAGE Game Software Components Repository for Supporting Applied Game Development", International Journal of Serious Games, Volume 4, Issue 3, ISSN: 2384-8766, pp. 59-71, http://dx.doi.org/10.17083/ijsg.v4i3.171, 2017.

[18] B. Bontchev and O. Georgieva, O. "Playing style recognition through an adaptive video game", Computers in Human Behavior, No. 82, pp.136-147, https://doi.org/10.1016/j.chb.2017.12.040, 2018. 